\section{Factors Influencing Children's Appraisals of Interparental Conflict: The Role of Parent-Child Relationship Quality}

Journal of Family Issues

$1-23$

(C) The Author(s) 2020

Article reuse guidelines: sagepub.com/journals-permissions DOI: $10.1177 / 0192513 \times 20910765$ journals.sagepub.com/home/jfi

(S)AGE

\author{
Şule Selçuk' (iD), Zülal İşcanoğlu² (D), \\ Melike Sayıl ${ }^{3}$, Nebi Sümer ${ }^{4}$, \\ and Sibel Kazak Berument ${ }^{5}$
}

\begin{abstract}
The cognitive contextual model proposes that children's appraisals of interparental conflict (IPC) can influence their adjustment. In addition, previous research revealed that interparental disputes may reflect on parentchild relationship that is linked with children's self-blame and threat appraisals concerning IPC. However, there is a scarcity of research directly addressing the intervening role of the parent-child relationship on children's appraisals of IPC. Thus, we investigated the mediating role of different aspects of the parent-child relationship (i.e., psychological control, warmth, and attachment security) in the link between IPC and self-blame and threat appraisals. Participants were 1,309 children, their mothers, and their fathers. SEM analyses indicated that higher IPC was related to higher parental psychological control and lower child attachment security, which in turn was associated
\end{abstract}

\footnotetext{
'Kastamonu University, Kastamonu, Turkey

${ }^{2}$ Çankaya University, Ankara, Turkey

${ }^{3}$ TED University, Ankara, Turkey

${ }^{4}$ Sabancı University, İstanbul, Turkey

${ }^{5}$ Middle East Technical University, Ankara, Turkey

\section{Corresponding Author:}

Şule Selçuk, Department of Psychology, Faculty of Arts and Sciences, Kastamonu University, Kuzeykent, Campus, Kastamonu, 37I50, Turkey.

Email: sselcuk@kastamonu.edu.tr
} 
with higher self-blame or threat appraisals. The pattern of relationships was similar across child and parent gender.

\section{Keywords}

interparental conflict, psychological control, parental warmth, attachment security, self-blame, threat appraisal

Cross-sectional and longitudinal research across different cultures has consistently demonstrated that interparental conflict (IPC) is associated with child or adolescent maladjustment, such as internalizing and externalizing problems (Bradford et al., 2003; Gerard et al., 2006; Schoppe-Sullivan et al., 2007). The cognitive contextual framework (Grych \& Fincham, 1990), one of the prominent theories attempting to explain this well-established link, proposes that the influence of exposure to IPC on child functioning depends on how children appraise the conflict. According to this framework, children actively interpret disputes between their parents and may develop some dysfunctional attributions regarding the conflict (Grych \& Fincham, 1990). For instance, they may expect harmful consequences for themselves or their family and may anticipate danger and fear (i.e., appraisal of threat), and/or put the blame and responsibility for the conflict on themselves (i.e., appraisal of selfblame) (Grych, 1998; Grych \& Fincham, 1990).

Some previous research indicates that children's interpretation of IPC, rather than their perception of its features, is particularly crucial for child adjustment. For instance, Grych et al. (1992) demonstrated that fourth-and fifth-grade children's subjective evaluations of IPC (i.e., self-blame and threat) were related to internalizing problems even when their perceptions concerning objective features of the conflict (e.g., frequency and intensity) were controlled, but not vice versa. Similarly, Dadds et al. (1999) revealed that adolescents' appraisals of self-blame and threat explained unique variance in behavioral problems controlling for perceived frequency and intensity of IPC. Overall, it seems that children who tend to blame themselves and experience threat when the conflict occurs are at greater risk of developing adjustment problems (Mueller et al., 2015).

However, there is still little known about how children appraise threat in response to IPC or come to blame themselves. The present study set out to explore the underlying mechanisms that may better explain their response to IPC. Although, the parent-child relationship has been studied a lot as the mediator of the association between IPC and child adjustment, its role in children's IPC appraisals has been relatively understudied. Therefore, we specifically 
aimed to investigate the intervening role of the perceived parent-child relationship in the association between parent-reported IPC and children's selfblame and threat appraisals.

\section{Interparental Conflict and Parent-Child Relationship}

The interdependent nature of marital and parent-child relationships has been reported in various studies using different approaches such as the spillover hypothesis, which proposed that marital quality spills over into parent-child interaction (Erel \& Burman, 1995; Snyder, 1998). More specifically, it emphasizes that emotional distress resulting from IPC may undermine the parentchild bond and the parents' ability to provide warmth and structure to their children (Erel \& Burman, 1995). Similarly, the emotional security hypothesis suggests that IPC disturbs the parent-child relationship and ultimately undermines children's feelings of emotional security (Davies \& Cummings, 1994). Longitudinal, cross-sectional, and daily reporting studies conducted with children and adolescents and mostly guided by these two approaches confirmed these propositions (e.g., Buehler \& Gerard, 2002; Doyle \& Markiewicz, 2005; El-Sheikh \& Elmore-Staton, 2004; Gerard et al., 2006; Sherrill et al., 2017; Sturge-Apple et al., 2008). Meta-analyses also indicated that there is a moderate relationship (Cohen's $d=.46$ and -.62) between IPC and parenting practices (Erel \& Burman, 1995; Krishnakumar \& Buehler, 2000).

Psychological control, warmth, and attachment security are among the most studied aspects of the parent-child relationship and may have unique relationships with IPC. Parental warmth is defined as expressed positive emotions and behaviors towards children including love, approval, closeness, and support (Rohner, 2008; Schaefer, 1965), and psychological control refers to manipulative and intrusive behaviors, especially those that invade the psychological world of children (Barber, 1996). Indeed, it has been found that IPC is linked with lower parental warmth and higher psychological control (e.g., Bradford et al., 2003; Li et al., 2011; Sayıl et al., 2019). For instance, a longitudinal study conducted with children and adolescents aged between 8 and 16 years revealed that parent-reported IPC predicted lower behavioral control (composite of parent and child report), lower psychological autonomy (parent report), and lower parental warmth (composite of parent and child report) one year later (Schoppe-Sullivan et al., 2007). Similarly, a crosssectional study conducted with mothers of children aged between 6 and 12 years showed that destructive IPC is positively related to psychological control (Coln et al., 2013).

The other aspect of parent-child relationship, attachment security, refers to children's ability to view their attachment figures as available and responsive 
when in distress (Bowlby, 1982). The emotional security hypothesis proposes that children who are exposed to high levels of IPC are more likely to be insecurely attached to their parents (Davies \& Cummings, 1994). Moreover, previous works confirmed that IPC is negatively related to children's attachment security to their parents (e.g., Brock \& Kochanska, 2016; El-Sheikh \& ElmoreStaton, 2004; Finger et al., 2009). For instance, Finger and colleagues (2009) demonstrated that mother-reported IPC is negatively linked with infants' attachment security to mothers that was evaluated with Strange Situation procedure. Parallel to this finding, a longitudinal study indicated that observed IPC when children are 6 months of age was inversely related to (parent-reported) attachment security to both parents when children were 3 years of age (Frosch et al., 2000). Furthermore, a cross-sectional study conducted with sixth- through eighth-grade students showed that IPC is positively linked with parent-child attachment insecurity with the mediating role of parenting difficulties (Davies et al., 2002). These findings imply that when children are exposed to IPC, they may worry that their parents will not be available to meet their needs and may develop some security concerns (see Davies \& Cummings, 1994).

Although attachment security is closely related to parental warmth (see Karavasilis et al., 2003), as indicated by Cummings George, et al. (2013), it represents a lasting emotional bond rather than the present warmth of relations between child and parent. As they are related but distinct constructs, they may be differentially related to IPC and children's IPC appraisals. Therefore, we integrated, in addition to psychological control, these other two aspects of the parent-child relationship in the suggested model in order to reveal their unique and combined relationships with other constructs.

\section{Parent-Child Relationship and Children's Conflict Appraisals}

A number of studies have found that children's self-blame and threat appraisals increase the risk for maladjustment (e.g., Grych et al., 2003), which have, in turn, invited more-in-depth investigation of possible factors that may explain these appraisals. It was proposed and/or confirmed that conflict properties (i.e., frequency, intensity, content, and resolution of the conflict) and contextual factors such as previous exposure to IPC, age, gender, and temperament shape children's IPC appraisals (Grych, 1998; Grych \& Finham, 1990, 1993; Grych et al., 2004). For instance, it was shown that previous exposure to frequent and hostile conflict may lead children to view IPC as more threatening since it sensitizes them to future conflicts (Grych, 1998; Grych et al., 2003).

Previous research also demonstrated that the parent-child relationship may shape children's IPC appraisals. For instance, it was shown that higher perceived paternal acceptance or supportive parent-child relationship is 
related to children's lower threat appraisal (Grych, 1998). Similarly, Grych and colleagues (2004) showed that maternal and paternal closeness are negatively associated with adolescents' threat and self-blame appraisals, respectively. Furthermore, in line with the suggestions of the emotional security hypothesis (see Davies \& Cummings, 1994), it was demonstrated that 8- to 12-year-old children who are less securely attached to their parents, particularly fathers, tend to perceive IPC as a threat to themselves and family harmony, and they are also more likely to blame themselves for the conflict (DeBoard-Lucas et al., 2010). Therefore, given that IPC undermines positivity among family members and the emotional climate of families (Erel \& Burman, 1995; Fosco \& Grych, 2013), parent-child relationship quality may be one of the most important mechanisms that explain the link between exposure to IPC and children's IPC appraisals.

Past studies have shown that, besides its moderating function (e.g., DeBoard-Lucas et al., 2010; Grych, 1998; Grych \& Fincham, 1990), the parent-child relationship plays a mediating role in the link between IPC and children's appraisals of disputes (e.g., Figge et al., 2018). For instance, a cross-sectional study revealed that child-reported IPC is associated with parental positivity and negativity (i.e., parent-reported expressed positive and negative affect), which in turn is related to children's self-blame appraisals (Fosco \& Grych, 2007). Moreover, a longitudinal study conducted with mother-child dyads indicated that children's perceived parent-child relationship quality partially mediates the association between mother-reported interparental violence (i.e., threats of violence, physical aggression, and sexual violence) and children's coping efficacy appraisals (Figge et al., 2018). Therefore, guided by the emotional security hypothesis and from recent findings summarized earlier, we thought that the parent-child relationship might mediate the link between exposure to IPC and children's IPC appraisals.

\section{The Role of Child and Parent Gender}

As boys and girls have different socialization experiences, the influence of the conflict and the meanings attributed to IPC may differ among boys and girls (see Grych, 1998; Grych \& Fincham, 1990; Snyder, 1998). Even though some studies did not reveal any gender differences (e.g., Grych \& Fincham, 1993), several studies confirmed that girls and boys might attribute different meanings to IPC. Some of these studies demonstrated that boys are more likely to view IPC as threatening and/or that girls tend to feel more distress and blame themselves for the conflict (Cummings et al., 1994; Grych, 1998). However, some studies have revealed opposite findings (e.g., Dadds et al., 1999). In addition, it was shown that parent-reported IPC is more strongly 
related to girls' attachment security to parents than boys' attachment security (Brock \& Kochanska, 2016). Moreover, a longitudinal study indicated that IPC is more likely to lead to increased use of psychological control only for boys (Sturge-Apple et al., 2004). However, in a meta-analysis, the link between IPC and the parent-child relationship was found to be stronger for girls compared to boys (Krishnakumar \& Buehler, 2000).

Previous research also indicated that IPC may be differentially associated with children's relationships with their mothers and fathers (see Coiro \& Emery, 1998; Kaczynski et al., 2006). Fathering vulnerability hypothesis emphasizes that the father-child relationship is more vulnerable to life stress compared to the mother-child relationship (Goeke-Morey \& Cummings, 2007). For instance, Stroud et al. (2011) found that IPC spills over into fathers' responsiveness to their children aged 3 to 6 years more strongly compared to mothers' responsiveness. In line with this finding, it was demonstrated that infants tend to attach securely to their fathers who view the parental role as important, but only if IPC is low and positive engagement is high (Wong et al., 2009). A meta-analysis exploring the association between IPC and parenting also supported the fathering vulnerability hypothesis (Krishnakumar \& Buehler, 2000). Although there are also some findings indicating no difference based on parent gender (e.g., Erel \& Burman, 1995), it is argued that there is more qualified support for fathering vulnerability hypothesis (see Cummings Goeke-Morey, et al., 2013).

In addition, as boys and girls tend to identify with fathers and mothers, respectively, it was suggested that IPC or marital quality may be more likely to disturb an opposite-sex parent child relationship compared to a same-sex one (Osborne \& Fincham, 1996). Some research findings confirmed that IPC is more strongly associated with a perceived opposite-sex parent child relationship. For instance, it was found that fathers who reported lower marital satisfaction were more likely to exhibit a negative affect towards their daughters than towards their sons (Kerig et al., 1993). Moreover, it was shown that IPC has a stronger link with perceived negativity in a mother-son relationship compared to a father-son relationship (Osborne \& Fincham, 1996). However, there are also some research findings demonstrating that IPC tends to intervene more with father-son relationships than with father-daughter relationship (see Cummings, Goeke-Morey, et al., 2013). Furthermore, given that children may develop different attachment representations to their mothers and fathers (Bretherton \& Munholland, 2016), attachment security in different parent-child dyads may play a differential role in children's IPC appraisals.

Overall, there are mixed findings in the literature regarding the moderating role of child and parent gender in the association of IPC with the 
parent-child relationship and children's IPC appraisals. Nevertheless, overall past findings have indicated the importance of attending to both child and parent gender while investigating the explanatory role of the parent-child relationship in children's IPC appraisals.

\section{The Present Study}

This study aimed to examine the mediating role of different aspects of the parent-child relationship in the association between exposure to IPC and children's IPC appraisals. As a secondary goal, we examined possible differences in the suggested relationships as a function of parent and child gender. Therefore, we first tested suggested links for the whole sample separately for mothers and fathers, and then conducted multi-group analyses for each model in order to compare the proposed paths for girls and boys. We collected information from multiple sources: IPC was assessed by both mothers and fathers, and IPC appraisals and three aspects of the parent-child relationship were reported by children.

As previous work demonstrated that IPC undermines the quality of the parent-child relationship, we expected that IPC would be positively associated with psychological control, whereas it would be negatively linked with warmth and attachment security. In addition, as psychologically controlling parents tend to induce guilt and behave intrusively (Barber, 1996), we hypothesized that being exposed to higher levels of psychological control would be linked with higher self-blame and threat. Furthermore, we expected both warmth and attachment security to be inversely related to self-blame and threat since strong emotional bond and supportive behaviors may make children believe that their parents will protect them against possible harm and attribute temporary reasons to IPC (see Grych \& Fincham, 1990). To summarize, we hypothesized that higher IPC would be associated with higher psychological control, lower warmth, and lower attachment security, which in turn would be linked with higher self-blame and threat appraisals. Because existing research does not provide consistent results in terms of the moderating role of child and parent gender, we did not have specific hypotheses regarding our second aim.

Several studies have tested the two-step mediating chain linking IPC and child outcomes (e.g., internalizing and externalizing problems) via poor parenting (including lower acceptance/warmth) and attachment security (see, Davies et al., 2002; Doyle \& Markiewicz, 2005; Frosch et al., 2000). However, we particularly aimed to reveal whether attachment security explains additional variance in children's IPC appraisals above and beyond parental warmth or vice versa. Therefore, we evaluated the simultaneous mediating role of attachment security and warmth in the suggested relationships. 


\section{Method}

\section{Participants}

A total of 1,309 fourth- $(49.4 \%)$ and fifth-grade $(50.6 \%)$ students $\left(M_{\text {age }}=\right.$ $10.15, S D=.65)$, their mothers $\left(M_{\text {age }}=36.43, S D=5.03\right)$, and their fathers $\left(M_{\text {age }}=40.71, S D=5.45\right)$ participated in the study. Participants were dominantly Turkish and were recruited from different geographical regions in Turkey such as a large city (Ankara, population approximately 5.5 million, $n=233$ ) and three relatively smaller ones (with populations ranging from 1.3 to 1.8 million, $n=1076)$. The number of girls was $656\left(M_{\text {age }}=10.13\right.$, $S D=.65)$ and boys was $653\left(M_{\text {age }}=10.17, S D=.64\right)$. The socioeconomic status of participants was determined as low (38.4\%), lower-middle $(40.7 \%)$, middle $(18.4 \%)$, and upper-middle (2.4\%). Mothers' level of educational attainment was primary school (30.6\%), secondary school (13.4\%), high school $(30.6 \%)$, and college $(22.8 \%)$, and only a small portion was illiterate $(2.4 \%)$. Similarly, $0.8 \%$ of fathers were illiterate, and the rest of them were primary school (17.8\%), secondary school (15.3\%), high school (30.9\%), and college (34.8\%) graduates. Researchers read the demographic questions and questionnaires for illiterate parents and noted their answers. The sample consisted mostly $(97.1 \%)$ of intact families $(0.6 \%$ married, but mother and father live separately; $1.0 \%$ divorced and child lives with mother; and $0.2 \%$ divorced and child lives with father). The majority of mothers (99.3\%) and fathers $(99.0 \%)$ were biological parents of the child, $0.2 \%$ of mothers and fathers were adoptive parents, and $0.3 \%$ of mothers and $0.7 \%$ of fathers were step-parents.

\section{Procedure}

The sample for the present study was taken from a large project aiming to investigate the role of parenting, attachment, and proximal contextual factors (e.g., marital quality) on children's adjustment (Sümer et al., 2009). In this study, we only included children $(n=1,309)$ whose mothers and fathers both reported IPC among those who reported on their relationships both with their mothers and fathers. Their data was then compared in terms of study variables with that of children excluded from the study $(n=769)$. Independent samples t-test analyses showed that mothers $(M=1.70, S D=.38)$ and fathers $(M=1.68, S D=.33)$ of the present sample reported significantly less IPC compared to mothers $(M=1.75, S D=.38)$ and fathers $(M=1.72$, $S D=.36$ ) whose data were excluded from the present study (for mothers $t(1574)=2.39, p<.05$, Cohen's $d=.13$; for fathers $t(1471)=2.28, p<.05$, Cohen's $d=.12$ ). As the difference between mother- or father-reported IPC means was small and there was no difference between these two groups based 
on other study variables, it was assumed that the present sample was not biased. Data was collected from public schools that were randomly selected from a list obtained from the Turkish Ministry of Education. Parents approved their own and their children's participation in the study. Children completed the questionnaires in their classes during a regular class hour. The parents completed the questionnaires, which were taken and brought back by their children, at home. Written approval was obtained from the Institutional Review Board of the Middle East Technical University and the Turkish Ministry of Education to perform the study.

\section{Measures}

Interparental conflict. The O'Leary-Porter Conflict Scale (Porter \& O'Leary, 1980 ) that was adapted to Turkish (10 items) and five additional items (Sümer et al., 2009) were used to assess how often marital hostility behaviors (e.g., quarrels, sarcasm, and physical abuse) are performed in front of the child in general (e.g., "How often do you and/or your spouse display verbal hostility in front of your child?"). A 4-point Likert scale is used ranging from 1 (never) to 4 (always), with higher scores representing higher levels of marital conflict. The questionnaire was completed by mothers $(\alpha=.80)$ and fathers $(\alpha$ $=.77$ ) separately.

Parenting practices. Children reported parenting practices for their mothers and fathers separately. Items from highly validated questionnaires were adapted to Turkish as part of the project (Sümer et al., 2009), and the project team added several items (e.g., "Does your mother understand that you are sad before you say so?") in order to create culturally meaningful parenting items. In the present study, we used only the subscales regarding psychological control and warmth. In order to capture different aspects of parental psychological control, we used items representing intrusion (e.g., "Does your father interfere with your homework even if you do not want him to?"), comparison (e.g., "Does your mother show your friend as an example to you?"), and guilt induction (e.g., "Does your father say he will love you only if you do something that he wants?"). Based on the factor analysis, the parental psychological control scale assembled by the researchers consisted of 15 items; one item was developed by Olsen and colleagues (2002), two items were taken from Barber's (1996) questionnaire, and twelve items were developed by the project team (Sümer et al., 2009). As a result of the factor analysis, the project team also created a warmth scale (e.g., "Does your mother also get upset when she is angry at you?") consisting of 10 items; five of them were developed by Arrindell et al. (1999), one item was taken from Olsen et al.'s (2002) questionnaire, 
and four items were developed by the project team (Sümer et al., 2009). Children reported how often their parents perform each parenting behavior. Items were rated on a 4-point Likert scale ranging from 1 (never) to 4 (always). Internal consistencies for mother $(\alpha=.75)$ and father $(\alpha=.74)$ forms on the psychological control scale and mother $(\alpha=.73)$ and father $(\alpha=.75)$ forms on the warmth scale were found to be acceptable.

Children's attachment security. Kerns Security Scale (Kerns et al., 1996) was filled in by children for their mothers and fathers separately. The scale was designed to evaluate children's perceptions of security in their relationships with their mothers and fathers in middle childhood and early adolescence. It was adapted to Turkish by Sümer and Anafarta-Şendağ (2009). Factor analysis revealed a one-factor solution. Based on these analyses, the questionnaire consists of 15 items (e.g., "Some kids find it easy to trust their mom/father BUT other kids are not sure if they can trust their mom/father."). First, children were asked to indicate which statement was more convenient for them. And then they rated how much the kid in the statement resembles themselves on a 4-point scale, with higher scores indicating a more secure attachment. The scale showed adequate internal consistency for both attachment to mother $(\alpha=.77)$ and father $(\alpha=.80)$.

Children's interparental conflict appraisals. The two subscales of Children's Perception of Interparental Conflict Scale (Grych et al., 1992) that were used to evaluate children's IPC appraisals are threat perception (10 items; e.g., "When my parents argue I'm afraid that something bad will happen") and self-blame (16 items, e.g., "It's usually my fault when my parents argue"). It was adapted to Turkish first by Öz (1999), and then by Sümer et al. (2009). Factor analysis confirmed the two-factor solution. Children rated the items on a 3-point Likert scale ranging from 1 (false), to 2 (sort of true), and to 3 (true), so higher scores reflect higher perceived self-blame and threat in response to IPC. Threat $(\alpha=.82)$ and self-blame $(\alpha=.83)$ subscales showed acceptable internal consistencies.

\section{Results}

\section{Preliminary Analyses}

Zero-order bivariate correlations among study variables are presented in Table 1. It was revealed that mother-reported IPC, child-reported maternal psychological control, attachment to mother, self-blame, and threat appraisals were interrelated. However, child-reported maternal warmth was only correlated positively with attachment to mother and negatively with children's 
Table I. Zero-order Bivariate Correlations among the Study Variables.

\begin{tabular}{lcccccc}
\hline & 1 & 2 & 3 & 4 & 5 & 6 \\
\hline I. Interparental conflict & $.474^{* *}$ & $.068^{*}$ & $-.048^{+}$ & $-.084^{* *}$ & $.137^{* *}$ & $.107^{* *}$ \\
2. Psychological control & $.103^{* *}$ & $.662^{* *}$ & -.006 & $-.279 * *$ & $.404^{* *}$ & $.237^{* *}$ \\
3. Parental warmth & .003 & -.027 & $.649 * *$ & $.450^{* *}$ & $-.258^{* *}$ & $-.059^{*}$ \\
4. Attachment security & $-.134^{* *}$ & $-.339^{* *}$ & $.390^{* *}$ & $.577^{* *}$ & $-.344^{* *}$ & $-.276^{* *}$ \\
5. Self-blame & $.157^{* *}$ & $.396^{* *}$ & $-.216^{* *}$ & $-.316^{* *}$ & - & $.314^{* *}$ \\
6. Threat & $.122^{* *}$ & $.255^{* *}$ & -.023 & $-.205^{* *}$ & $.314^{* *}$ & - \\
\hline
\end{tabular}

Note. ${ }^{+} p=.08,{ }^{*} p<.05,{ }^{* *} p<.01$.

The values above the diagonal are for fathers; the values below the diagonal are for mothers; and correlations between variables for mothers and fathers are on the diagonal.

self-blame. Similarly, father-reported IPC, child-reported paternal psychological control, attachment to father, self-blame, and threat appraisals were interrelated.

In addition, one-way ANOVAs were conducted to examine if there were differences based on parent and child gender in terms of study variables (see Table 2). Results revealed that boys reported more maternal and paternal psychological control and more self-blame compared to girls. In addition, girls reported more maternal warmth and more secure attachment to mothers compared to boys. Parental gender differences showed that mothers reported more IPC compared to fathers. Subsequently, 2 X 2 (gender of parent X gender of child) mixed ANOVAs were conducted to test the interaction effect on child-reported psychological control, warmth, and attachment security with the parent gender as the within-subject variable (see Table 2). Results revealed that only attachment security differed across parent-child dyads. Follow-up analysis showed that girls reported higher attachment security to mothers compared to father-daughter, mother-son, and father-son dyads $(p \mathrm{~s}<.01)$.

\section{Main Analyses}

We conducted Structural Equation Modelling (SEM) Analyses with the lavaan package (Rosseel, 2012) and R software (R Core Team, 2016) in order to test our hypothesis that psychological control, warmth, and attachment security would mediate the relationship between IPC and children's IPC appraisals. Percentages of missing values for scale items ranged from $0 \%$ to $0.9 \%$. We used full information maximum likelihood estimation (FIML) to handle missing values in the data. To calculate parameter estimates, we used maximum likelihood estimation with robust standard errors (MLR) that is robust to non-normality in the data. We created parcels as indicators of latent 


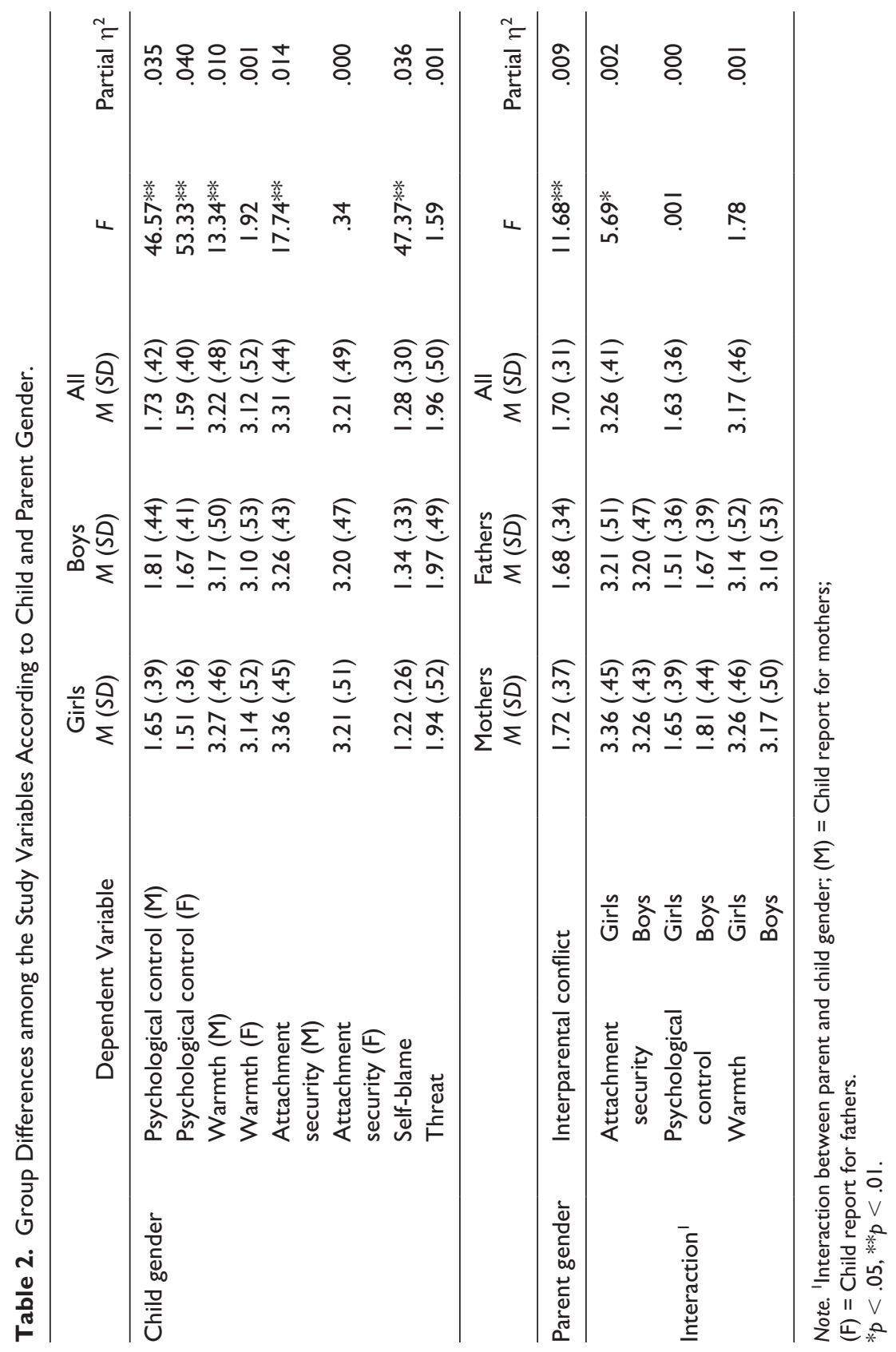


constructs by randomly assigning the items for each parcel. Only a latent variable of psychological control was represented by the mean scores of three subscales (i.e., intrusion, guilt induction, and comparison). IPC, attachment security, and self-blame had five indicators, and psychological control, warmth, and threat had three indicators. Self-blame and threat were allowed to covary in all models.

We first tested the full mediation model for both mothers and fathers, and then added direct paths from IPC to self-blame and threat in order to test the partial mediation model. We compared these nested models by SatorraBentler chi square difference test $(\Delta \mathrm{S}-\mathrm{B} \chi 2$; Satorra \& Bentler, 2001). Partial mediation models provided better fit to the data, for the mother model: $\Delta \mathrm{S}$ $\mathrm{B} \chi 2(2)=13.04$, for the father model: $\Delta \mathrm{S}-\mathrm{B} \chi 2(2)=11.45, p \mathrm{~s}<.01$. However, they provided almost adequate fit to the data: $\mathrm{S}-\mathrm{B} \chi 2(240 ; \mathrm{N}=$ $1309)=1085.49, p<.01, \mathrm{CFI}=.900, \mathrm{SRMR}=.082, \mathrm{RMSEA}=.052$ (90-CI: .049 - .055) for the mother model, and S-B $\chi 2(240 ; \mathrm{N}=1309)=$ $1087.21, p<.01, \mathrm{CFI}=.900, \mathrm{SRMR}=.087, \mathrm{RMSEA}=.052$ (90-CI: .049 - .055) for the father model. Therefore, based on suggested change by modification indices that is also conceptually meaningful, we added a covariance between warmth and attachment security. The re-specified models provided good fit to the data: $\mathrm{S}-\mathrm{B} \chi 2(239 ; \mathrm{N}=1309)=838.37, p<.01, \mathrm{CFI}=.929$, SRMR $=.059$, RMSEA $=.044$ (90-CI: .041 - .047) for the mother model, and $\mathrm{S}-\mathrm{B} \chi 2(239 ; \mathrm{N}=1309)=769.24, p<.01, \mathrm{CFI}=.938, \mathrm{SRMR}=.055$, RMSEA $=.041$ (90-CI: .038 - .044) for the father model. For both mother and father models, (a) IPC was positively related to psychological control and negatively to attachment security, (b) psychological control was positively and attachment security was negatively related to threat, (c) warmth was negatively associated with self-blame but not related to threat, and (d) IPC was directly related to both self-blame and threat. The negative link between attachment security and self-blame was significant only for the father model (see Figure 1).

Test of indirect effects was conducted with the delta method (Sobel, 1982) via lavaan package (see Rosseel, 2012) for both models, and it showed that IPC was indirectly related to self-blame via psychological control $(\beta=.08$ for the mother model, $\beta=.05$ for the father model, $p \mathrm{~s}<.02$ ). IPC was also indirectly linked with threat via psychological control $(\beta=.04$ for the mother model, $\beta=.03$ for the father model, $p$ s $<.02$ ) and attachment security $(\beta=.03$ for the mother model, $\beta=.04$ for the father model, $p \mathrm{~s}<.01)$. Warmth was not a significant mediator in either model. 


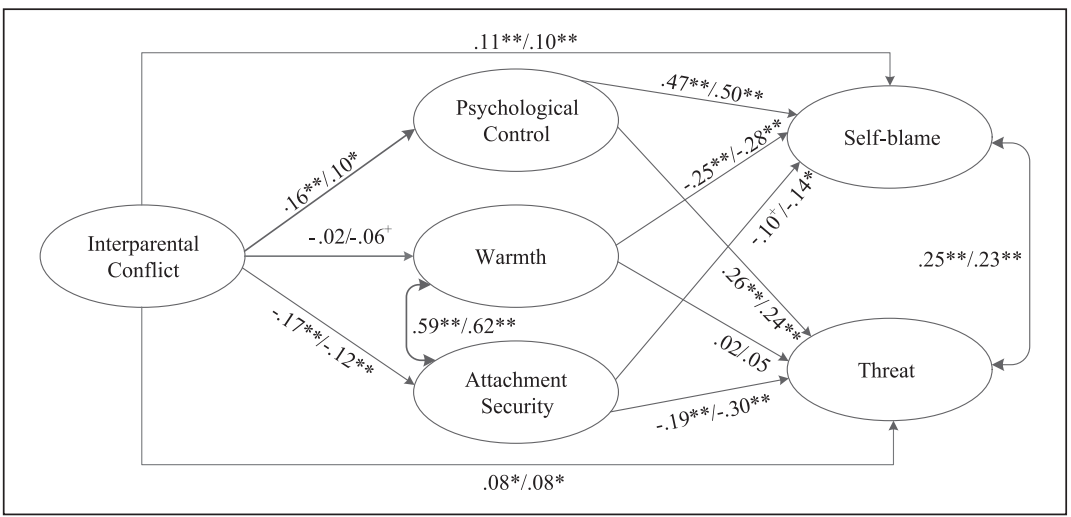

Figure I. Structural model of relations between interparental conflict, parentchild relationships, and children's self-blame and threat appraisals.

Note. ${ }^{+} p<.08,{ }^{*} p<.05,{ }^{*} p p<.01$.

First values stand for the mother model; the second for the father model.

\section{Moderator Role of Child Gender}

In order to investigate whether child gender moderates any of the reported relationships, we conducted multiple group SEM analysis for both the mother and father models. We first ran the conceptual (baseline) model without equality constraints between girls' and boys' model parameters. Second, we constrained factor-loading parameters to be equal across girls and boys, and then compared this constrained model with the baseline model. Satorra Bentler chi-square difference test revealed no significant differences between these nested models, which indicates that factor loadings were invariant across child gender, $\Delta \mathrm{S}-\mathrm{B} \chi 2(18)=27.5$ for the mother model and 24.9 for the father model, $p \mathrm{~s}>.10$. Third, we constrained both factor loadings and regression paths to be equal across girls and boys to explore whether associations between latent constructs were significantly different across child gender. Satorra Bentler chi-square difference test between this and the previous constrained model was also not significant for both the mother and father models, $\Delta \mathrm{S}-\mathrm{B} \chi 2(11)=11.7$ for the mother model and 15.7 for the father model, $p \mathrm{~s}>.10$. Thus, it was shown that child gender did not play a moderating role in either model.

\section{Discussion}

The present study investigated the explanatory role of the parent-child relationship in children's IPC appraisals in order to improve our understanding 
regarding the mechanisms shaping these appraisals. The primary contribution of the current study was to explore different aspects of the parent-child relationship as intervening mechanisms between IPC and children's IPC appraisals. In addition, different from previous research, we investigated whether this mediating relationship varies as a function of child and parent gender. In line with our hypothesis, findings indicate that both maternal and paternal psychological control play a mediating role in the association between IPC and children's self-blame or threat appraisals. In addition, as expected, it was revealed that children's attachment security to both mothers and fathers mediate the link between IPC and children's threat appraisal. However, contrary to our expectations, both maternal and paternal warmth did not play a mediating role in these relationships even though both maternal and paternal warmth were related to self-blame. Finally, it was shown that the pattern of relationships was similar for girls and boys.

\section{The Mediating Role of Parent-Child Relationship}

The intervening role of psychological control and attachment security implies that conflict between parents may be linked with children's threat and selfblame appraisals via its association with certain dimensions of parent-child relationship quality. This finding is in line with both spill-over (Erel \& Burman, 1995) and emotional security hypotheses (Davies \& Cummings, 1994). As these hypotheses suggested, it appeared that IPC may disturb parent-child relationship quality due to increased negative and insensitive parenting practices (in this case psychologically controlling behaviors) and damage to the emotional bond between parent and child (see Buehler \& Gerard, 2002; Davies \& Cummings, 1994).

We also confirmed findings of various studies conducted in different cultures indicating that IPC may be related to poor parent-child relationship (e.g., Brock \& Kochanska, 2016; Li et al., 2011), and that parent-child relationship may mediate the link between IPC and children's IPC appraisals (e.g., Figge et al., 2018). However, previous studies evaluated either overall or a specific aspect (positivity and negativity) of the quality of the parentchild relationship as an intervening mechanism linking exposure to IPC with children's IPC appraisals (see Figge et al., 2018; Fosco \& Grych, 2007). In that sense, the present study extends prior findings by demonstrating the intervening role of different aspects of parent-child relationship (i.e., psychological control and attachment security) that is robust across child and parent gender.

Current findings suggest that when children realize that their parents behave more intrusively and manipulatively, and when the emotional bond 
with their parents is weakened, they might think that these changes happen as the conflict between their parents result from something related to themselves (i.e., self-blame). The disrupted relationship between their parents might also make them think that life will get worse for themselves and their family (i.e. perception of threat), given that parents, who provide safety, are primary agents in the family. For instance, parents' psychologically controlling behaviors such as constantly comparing their children with others and intruding into their thoughts and feelings may lead children to think that they will become the target of parental anger. In addition, children may tend to believe that the conflict occurs due to their faults when they are exposed to specific psychological control practices such as guilt induction. On the other hand, children may tend to think that the conflict results from temporary and external causes if IPC does not undermine their close relationships with their parents (see Fincham et al., 1994; Grych \& Fincham, 1990).

Contrary to our expectations, both maternal and paternal warmth did not play a mediating role in the link between IPC and children's self-blame and threat appraisals. Even though we aimed to see whether attachment security and warmth have unique associations with IPC, self-blame, and threat, the high correlation between them suggests that they are redundant constructs. It seems that, compared to warmth, attachment security has a stronger relationship with IPC and children's IPC appraisals, which makes sense given that it reflects much more than the representations of affectionate and supportive behaviors (see Cummings, George, et al., 2013).

Parallel to previous research (e.g., Grych et al., 2004; Siffert et al., 2012), the present findings confirmed the negative relationship between maternal or paternal warmth and self-blame. This finding suggests that when parents are affectionate and supportive towards their children, children are less likely to blame themselves for disagreements between their parents. In that case, children may be more likely to attribute responsibility for the conflict to their parents or some external factors.

\section{Differences Based on Child and Parent Gender}

As mentioned earlier, since previous research has provided mixed findings, we did not have specific hypotheses regarding the moderating role of child and parent gender. The findings of the current study indicated that child gender does not moderate any of the reported relationships although boys, compared to girls, reported to experience higher maternal and paternal psychological control and less maternal warmth, and tended to be less securely attached to their mothers and experienced more self-blame. In addition, it was revealed that associations among study variables were similar to a great 
extent based on parent gender. This finding confirms the findings of a previous study conducted with Turkish adolescents in which the associations between IPC and parenting practices including psychological control were similar across mothers and fathers (Sayıl et al., 2019). Overall, current findings suggest that, in middle childhood, IPC similarly relates to parent-child relationship across different parent-child dyads. Therefore, our findings do not support the fathering vulnerability hypothesis (see Goeke-Morey \& Cummings, 2007) and contradict with some previous findings indicating that IPC more strongly relates to opposite-sex parent-child relationships than same-sex parent-child relationships (e.g., Osborne \& Fincham, 1996). A longitudinal study showed that marital negativity leads to a decrease in paternal but not maternal warmth (Schofield et al., 2009). Therefore, it may be that IPC undermines fathers' affectionate and supportive behaviors more strongly compared to corresponding maternal behaviors, in the long run. Therefore, future studies with longitudinal designs conducted in Turkish context may enlighten us about these contradictions.

Aforementioned findings also imply that poor parenting by both mothers and fathers may lead both girls and boys to blame themselves and feel threat in response to IPC. It is known that parents are primary figures providing important psychological resources during childhood (see Pomerantz \& Thompson, 2008), and their emotional support plays a vital role in children's lives especially during stressful times (Denham et al., 2002) regardless of child gender. That may be the reason why girls and boys react with similar cognitive responses to IPC when they experience decreased quality of relationship either with mothers or fathers. However, it is also likely that we may have failed to reveal the moderating role of child gender as our sample mainly consisted of "normal" families with low levels conflict. Child gender may be more likely to moderate the reported relationships for families with high levels of conflict, given that affective, cognitive, and behavioral responses and attribution of blame to fathers may differ across boys and girls depending on the frequency and/or intensity of the conflicts (see Grych, 1998; Grych et al., 2003).

\section{Limitations and Future Directions}

Although there are several strengths to the current study, including relatively large sample size, use of multiple informants, and evaluation of various aspects of parent-child relationships, there are also some limitations that need to be addressed in future studies. First, the cross-sectional nature of the study requires caution in evaluating the reported findings. Although we interpreted the findings in terms of the influence of IPC on children's IPC appraisals via the parent child relationship, it is also possible that children's exposure to IPC 
leads to maladaptive IPC appraisals, which in turn affect their perceived quality of the relationship with their parents. Therefore, longitudinal research studies should investigate these alternative explanations with cross-lagged mediation models. Future studies may also compare the mediating versus moderating role of the parent-child relationship and/or extend the present model by including child adjustment as the ultimate outcome. We investigated only two types of IPC appraisals emphasized by the cognitive contextual framework. Therefore, future studies might examine children's coping and triangulation appraisals to understand the role of the parent-child relationship on children's IPC appraisals more comprehensively. In addition, it is crucial to consider together the nature of IPC (e.g., severity, intensity, constructive vs. deconstructive, and overt vs. covert conflict) and familial factors as well as child characteristics (e.g., temperament) in order to understand how children perceive IPC (Cummings et al., 1994; Dadds et al., 1999; Grych, 1998; Snyder, 1998; Zimet \& Jacob, 2001). Furthermore, it must be noted that the present sample consisted of relatively more cohesive families with low levels of conflict, given that they reported low levels of IPC, psychological control, self-blame, and threat, and high levels of warmth and attachment security. Therefore, reported pattern of relationships may differ in families with high levels of conflict and less positive parent-child relationships. Finally, as certain aspects of parent-child relationships seem to be critical mechanisms accounting for children's IPC appraisals, future studies should investigate both potential risk and buffering factors affecting the spillover of marital problems on the parent-child relationship. If we can detect under what circumstances IPC spills over to impact parent-child relationships, we will be able to gain leverage in terms of intervening in the spillover processes for families with conflictual marital relationships and decreasing the probability of children experiencing adjustment problems.

\section{Conclusion}

In summary, the present study revealed the role of specific interpersonal family dynamics in children's IPC appraisals. The findings imply that even though IPC may reflect on the parent-child relationship, if mothers and/or fathers continue to be the secure base, then children may be less likely to perceive the conflict as threating for themselves or for the family. It also seems that an intact emotional bond between parents and the child may prevent children's self-blaming tendencies. On the other hand, our findings also suggest that if parents tend to use psychologically controlling behaviors, then children are more likely to think that conflicts occur due to their faults and tend to anticipate harmful consequences. Taken together, these findings 
underscore the importance of parents' preserving their positive relationship with children in order to minimize children's maladaptive cognitions concerning the conflict.

As Cummings and his colleagues (1994) emphasized, children's appraisals of IPC may be a better predictor of their adjustment than parent-reported IPC. Therefore, possible mechanisms for children's maladaptive appraisals should be investigated thoroughly across different cultures.

\section{Declaration of Conflicting Interests}

The authors declared no potential conflicts of interest with respect to the research, authorship, and/or publication of this article.

\section{Funding}

The authors disclosed receipt of the following financial support for the research, authorship, and/or publication of this article: This research was supported by The Scientific and Technological Research Council of Turkey (Project No: 105K102, 2005-2008). We thank all participating children and parents.

\section{ORCID iDs}

Şule Selçuk (iD) https://orcid.org/0000-0003-0933-8174

Zülal İşcanoğlu (iD) https://orcid.org/0000-0003-3221-6861

\section{References}

Arrindell, W. A., Sanavio, E., Aguilar, G., Sica, C., Hatzichristou, C., Eisemann, M., Recinos, L. A., Gaszner, P., Peter, M., Battagliese, G., Kállai, J., \& van der Ende, J. (1999). The development of a short form of the EMBU: Its appraisal with students in Greece, Guatemala, Hungary, and Italy. Personality and Individual Differences, 27(4), 613-628.

Barber, B. K. (1996). Parental psychological control: Revisiting a neglected construct. Child Development, 67(1), 3296-3319.

Bowlby, J. (1982). Attachment and loss. Vol. l: Attachment (2 ${ }^{\text {nd }}$ Ed.). Basic Books.

Bradford, K., Barber, B. K., Olsen, J. A., Ward, D., \& Stolz, H. E. (2003). A multinational study of interparental conflict, parenting, and adolescent functioning: South Africa, Bangladesh, China, India, Bosnia, Germany, Palestine, Colombia, and the United States. Marriage and Family Review, 35(3-4), 107-137.

Bretherton, I., \& Munholland, K. A. (2016). The internal working model construct in light of contemporary neuroimaging research. In J. Cassidy \& P. R. Shaver (Eds.), Handbook of attachment: Theory, research, and clinical applications $\left(3^{\text {rd }}\right.$ ed., pp. 63-90). The Guilford Press.

Brock, R. L., \& Kochanska, G. (2016). Interparental conflict, children's security with parents, and long-term risk of internalizing problems: A longitudinal study from ages 2 to 10. Development and Psychopathology, 28(1), 45-54. 
Buehler, C., \& Gerard, J. M. (2002). Marital conflict, ineffective parenting, and children's and adolescents' maladjustment. Journal of Marriage and Family, 64(1), 78-92.

Coiro, M. J., \& Emery, R. E. (1998). Do marriage problems affect fathering more than mothering? A quantitative and qualitative review. Clinical Child and Family Psychology Review, 1(1), 23-40.

Coln, K. L., Jordan, S. S., \& Mercer, S. H. (2013). A unified model exploring parenting practices as mediators of marital conflict and children's adjustment. Child Psychiatry and Human Development, 44(3), 419-429.

Cummings, E. M., Davies, P. T., \& Simpson, K. S. (1994). Marital conflict, gender, and children's appraisals and coping efficacy as mediators of child adjustment. Journal of Family Psychology, 8(2), 141-149.

Cummings, E. M., George, M. R., Koss, K. J., \& Davies, P. T. (2013). Parental depressive symptoms and adolescent adjustment: Responses to children's distress and representations of attachment as explanatory mechanisms. Parenting: Science and Practice, 13(4), 213-232.

Cummings, E. M., Goeke-Morey, M. C., \& Raymond, J. (2013). Fathers in family context: Effects of marital quality and marital conflict. In M. E. Lamb (Ed.), The role of the father in child development ( $4^{\text {th }}$ ed., pp. 196-221). John Wiley \& Sons, Inc.

Dadds, M. R., Atkinson, E., Turner, C., Blums, G. J., \& Lendich, B. (1999). Family conflict and child adjustment: Evidence for a cognitive-contextual model of intergenerational transmission. Journal of Family Psychology, 13(2), 194-208.

Davies, P. T., \& Cummings, E. M. (1994). Marital conflict and child adjustment: An emotional security hypothesis. Psychological Bulletin, 116(3), 387-411.

Davies, P. T., Harold, G. T., Goeke-Morey, M. C., \& Cummings, E. M. (2002). Child emotional security and interparental conflict. Monographs of the Society for Research in Child Development, 67(3), 1-127.

DeBoard-Lucas, R. L., Fosco, G. M., Raynor, S. R., \& Grych, J. H. (2010). Interparental conflict in context: Exploring relations between parenting processes and children's conflict appraisals. Journal of Clinical Child and Adolescent Psychology, 39(2), 163-175.

Denham, S. A., von Salisch, M., Olthof, T., Kochanoff, A., \& Caverly, S. (2002). Emotional and social development in childhood. In P. K. Smith \& C. H. Hart (Eds.), Blackwell handbook of childhood social development (pp. 307-328). Oxford: Blackwell Publishers.

Doyle, A. B., \& Markiewicz, D. (2005). Parenting, marital conflict and adjustment from early- to mid-adolescence: Mediated by adolescent attachment style? Journal of Youth and Adolescence, 34(2), 97-110.

El-Sheikh, M., \& Elmore-Staton, L. (2004). The link between marital conflict and child adjustment: Parent-child conflict and perceived attachments as mediators, potentiators, and mitigators of risk. Development and Psychopathology, 16(3), 631-648.

Erel, O., \& Burman, B. (1995). Interrelatedness of marital relations and parent-child relations: A meta-analytic review. Psychological Bulletin, 118(1), 108-132. 
Figge, C. J., Martinez-Torteya, C., Bogat, G. A., \& Levendosky, A. A. (2018). Child appraisals of interparental conflict: The effects of intimate partner violence andparent-child relationship quality. Journal of Interpersonal Violence, 1, 1-22.

Fincham, F. D., Grych, J. H., \& Osborne, L. N. (1994). Does marital conflict cause child maladjustment? Directions and challenges for longitudinal research. Journal of Family Psychology, 8(2), 128-140.

Finger, B., Hans, S. L., Bernstein, V. J., \& Cox, S. M. (2009). Parent relationship quality and infant-mother attachment. Attachment and Human Development, 11(3), 285-306.

Fosco, G. M., \& Grych, J. H. (2007). Emotional expression in the family as a context for children's appraisals of interparental conflict. Journal of Family Psychology, 21(2), 248-258.

Fosco, G. M., \& Grych, J. H. (2013). Capturing the family context of emotion regulation: A family systems model comparison approach. Journal of Family Issues, 34(4), 557-578.

Frosch, C., Mangelsdorf, S., \& McHale, J. (2000). Marital behaviour and the security of preschooler-parent attachment relationships. Journal of Family Psychology, 14(1), 144-161.

Gerard, J. M., Krishnakumar, A., \& Buehler, C. (2006). Marital conflict, parent-child relations, and youth maladjustment: A longitudinal investigation of spillover effects. Journal of Family Issues, 27(7), 951-975.

Goeke-Morey, M. C., \& Cummings, E. M. (2007). Impact of father involvement: A closer look at indirect effects models involving marriage and child adjustment. Applied Developmental Science, 11(4), 221-225.

Grych, J. H. (1998). Children's appraisals of interparental conflict: Situational and contextual influences. Journal of Family Psychology, 12(3), 437-453.

Grych, J. H., \& Fincham, F. D. (1990). Marital conflict and children's adjustment: A cognitive-contextual framework. Psychological Bulletin, 108(2), 267-290.

Grych, J. H., \& Fincham, F. D. (1993). Children's appraisals of marital conflict: Initial investigations of the cognitive-contextual framework. Child Development, 64(1), 215-230.

Grych, J. H., Harold, G. T., \& Miles, C. J. (2003). A prospective investigation of appraisals as mediators of the link between interparental conflict and child adjustment. Child Development, 74(4), 1176-1193.

Grych, J. H., Raynor, S. R., \& Fosco, G. M. (2004). Family processes that shape the image of interparental conflict on adolescents. Development and Psychopathology, $16,649-665$.

Grych, J. H., Seid, M., \& Fincham, F. D. (1992). Assessing marital conflict from the child's perspective: The children's perception of interparental conflict scale. Child Development, 63(3), 558-572.

Kaczynski, K. J., Lindahl, K. M., Malik, N. M., \& Laurenceau, J. P. (2006). Marital conflict, maternal and paternal parenting, and child adjustment: A test of mediation and moderation. Journal of Family Psychology, 20(2), 199-208.

Karavasilis, L., Doyle, A. B., \& Markiewicz, D. (2003). Associations between parenting style and attachment to mother in middle childhood and adolescence. International Journal of Behavioral Development, 27(2), 153-164. 
Kerig, P. K., Cowan, P. A., \& Cowan, C. P. (1993). Marital quality and gender differences in parent-child interaction. Developmental Psychology, 29(6), 931-939.

Kerns, K. A., Klepac, L., \& Cole, A. (1996). Peer relationships and preadolescents' perceptions of security in the child-mother relationship. Developmental Psychology, 32(3), 457-466.

Krishnakumar, A., \& Buehler, C. (2000). Interparental conflict and parenting behaviors: A meta-analytic review. Family Relations, 49(1), 25-44.

Li, Y., Putallaz, M., \& Su, Y. (2011). Interparental conflict styles and parenting behaviors: Associations with overt and relational aggression among chinese children. Merrill-Palmer Quarterly, 57(4), 402-428.

Mueller, V., Jouriles, E. N., McDonald, R., \& Rosenfield, D. (2015). Children's appraisals and involvement in interparental conflict: Do they contribute independently to child adjustment? Journal of Abnormal Child Psychology, 43(6), 1041-1054.

Olsen, S. F., Yang, C., Hart, C. H., Robinson, C. C., Wu, P., Nelson, D. A., . . . Wo, J. (2002). Maternal psychological control and preschool children's behavioral outcomes in China, Russia, and the United States. In B. K. Barber (Ed.). Intrusive parenting: How psychological control affects children and adolescents? (pp. 235-262). Washington, DC: American Psychological Association.

Osborne, L. N., \& Fincham, F. D. (1996). Marital conflict, parent-child relationships, and child adjustment: Does gender matter? Merrill-Palmer Quarterly, 42(1), 48-75.

Öz, İ. P. (1999). The relationship between children's adjustment problems and their perceptions of marital conflict. (Unpublished master's thesis), Middle East Technical University, Ankara, Turkey.

Pomerantz, E. M., \& Thompson, R. A. (2008). Parents' role in children's personality development: The psychological resource principle. In O. P. John, R.W. Robins, \& L. A. Pervin (Eds.), Handbook of personality: Theory and research (Vol. 3, pp. 351-374). Guilford.

Porter, B., \& O’Leary, K. D. (1980). Marital discord and childhood behavior problems. Journal of Abnormal Child Psychology, 8(3), 287-295.

R Core Team. (2016). R: A language and environment for statistical computing [Computer software manual]. Vienna, Austria: R Foundadion for Statistical Computing. http://www.R-project.org/.

Rohner, R. P. (2008). Introduction: Parental acceptance-rejection theory studies of intimate adult relationships. Cross-Cultural Research, 42(1), 5-12.

Rosseel, Y. (2012). lavaan: Latent variable analysis ( $\mathrm{R}$ package version 3.3-1) [Computer software manual]. http://CRAN.R-project.org/package=lavaan

Satorra, A., \& Bentler, P. M. (2001). A scaled difference chi-square test statistic for moment structure analysis. Psychometrika, 66(4), 507-514.

Sayıl, M., Kındap Tepe, Y., \& Kumru, A. (2019). The relation between interparental conflict and adolescent's adjustment problems: The mediator role of parental control practices. Turkish Journal of Psychology, 34(83), 74-89. 
Schaefer, E. S. (1965). Children's reports of parental behavior: An inventory. Child Development, 36(2), 413-424.

Schofield, T. J., Conger, R. D., Martin, M. J., Stockdale, G. D., Conger, K. J., \& Widaman, K. F. (2009). Reciprocity in parenting of adolescents within the context of marital negativity. Developmental Psychology, 45(6), 1708-1722.

Schoppe-Sullivan, S. J., Schermerhorn, A. C., \& Cummings, E. M. (2007). Marital conflict and children's adjustment: Evaluation of the parenting process model. Journal of Marriage and Family, 69(5), 1118-1134.

Sherrill, R. B., Lochman, J. E., DeCoster, J., \& Stromeyer, S. L. (2017). Spillover between interparental conflict and parent-child conflict within and across days. Journal of Family Psychology, 31(7), 900-909.

Siffert, A., Schwarz, B., \& Stutz, M. (2012). Marital conflict and early adolescents' self-evaluation: The role of parenting quality and early adolescents' appraisals. Journal of Youth and Adolescence, 41(6), 749-763.

Snyder, J. R. (1998). Marital conflict and child adjustment: What about gender? Developmental Review, 18(3), 390-420.

Sobel, M. E. (1982). Asymptotic confidence intervals for indirect effects in structural equation models. Sociological Methodology, 13, 290-312.

Stroud, C. B., Durbin, C. E., Wilson, S., \& Mendelsohn, K. A. (2011). Spillover to triadic and dyadic systems in families with young children. Journal of Family Psychology, 25(6), 919-930.

Sturge-Apple, M. L., Davies, P. T., Boker, S. M., \& Cummings, E. M. (2004). Interparental discord and parenting: Testing the moderating roles of child and parent gender. Parenting: Science and Practice, 4(4), 361-380.

Sturge-Apple, M. L., Davies, P. T., Winter, M. A., Cummings, E. M., \& Schermerhorn, A. (2008). Interparental conflict and children's school adjustment: The explanatory role of children's internal representations of interparental and parent-child relationships. Developmental Psychology, 44(6), 1678-1690.

Sümer, N., \& Anafarta-Şendağ, M. (2009). Attachment to parents during middle childhood, self-perceptions, and anxiety. Turkish Journal of Psychology, 24(63), 86-101.

Sümer, N., Sayıl, M., \& Berument, S. K., Doğruyol, B., Günaydın, G., Harma, M., Öztürk, A., Salman, S., \& Selçuk, E. (2009). Çocuğun gelişiminde bağlanma, ilgi-bakım ve aile dinamiklerinin etkisi. Project Granted by The Scientific and Technological Research Council of Turkey (Project No: 105K102).

Wong, M. S., Mangelsdorf, S. C., Brown, G. L., Neff, C., \& Schoppe-Sullivan, S. J. (2009). Parental beliefs, infant temperament, and marital quality: Associations with infant-mother and infant-father attachment. Journal of Family Psychology, 23(6), 828-838.

Zimet, D. M., \& Jacob, T. (2001). Influences of marital conflict on child adjustment: Review of theory and research. Clinical Child and Family Psychology Review, 4(4), 319-335. 